\title{
D3MOBILE METROLOGY WORLD LEAGUE: TRAINING SECONDARY STUDENTS ON SMARTPHONE-BASED PHOTOGRAMMETRY
}

\author{
J. P. Ortiz-Sanz ${ }^{1}$, M. Gil-Docampo ${ }^{1}$, T. Rego-Sanmartín ${ }^{2}$, M. Arza-García ${ }^{1}$, G. Tucci ${ }^{3}$, E. I. Parisi ${ }^{3, *}$, V. Bonora ${ }^{3}$, F. Mugnai ${ }^{3}$ \\ ${ }^{1}$ Civil and Geomatics Research Group - CIGEO. Dept. of Agroforestry Engineering. University of Santiago de Compostela, Lugo \\ (CampusTerra) 27002, Spain - (juan.ortiz, ml.gil, m.arza)@usc.es \\ ${ }^{2}$ Education, University and Vocational Training Department. Regional Government (Xunta de Galicia), Spain - \\ teresaregosanmartin@edu.xunta.es \\ ${ }^{3}$ Geomatics for Environment and Conservation of Cultural Heritage Laboratory - GECO. Dept. of Civil and Environmental \\ Engineering, University of Florence, Via di S. Marta 3, 50139, Florence, Italy - (grazia.tucci, ericaisabella.parisi, valentina.bonora, \\ francesco.mugnai)@unifi.it
}

Commission V, WG V/1

KEY WORDS: Education, 3-D Scanning, Mobile phones, STEM, Free apps, Challenges

\begin{abstract}
:
The advent of the smartphones brought with them higher processing capabilities and improved camera specifications which boosted the applications of mobile-based imagery in a range of domains. One of them is the 3-D reconstruction of objects by means of photogrammetry, which now enjoys great popularity. This fact brings potential opportunities to develop educational procedures in high schools using smartphone-based 3-D scanning techniques. On this basis, we designed a Project Based e-Learning (PBeL) initiative to introduce secondary students to the disciplines of photogrammetry through the use of their mobile phones in an attractive and challenging way for them. The paper describes the motivation behind the project "D3MOBILE Metrology World League", supported by ISPRS as part of the "Educational and Capacity Building Initiative 2020" programme. With this Science, Technology, Engineering and Mathematics (STEM) initiative, we implement a methodology with the format of an international competition, that can be adapted to daily classwork at the high school level anywhere in the world. Therefore, the championship is essentially structured around a collection of well-thought-out e-learning materials (text guidelines, video tutorials, proposed exercises, etc.), providing a more flexible access to content and instruction at any time and from any place. The methodology allows students to gain spatial skills and to practice other transversal abilities, learn the basics of photogrammetric techniques and workflows, gain experience in the 3-D modelling of simple objects and practice a range of techniques related to the science of measurement.
\end{abstract}

\section{INTRODUCTION}

In the last years, Information and Communications Technologies (ICTs) come to play a very large part in our lives. With them, also an increasing demand for geo-spatial and three-dimensional (3D) based products has come in a wide range of sectors (e.g. entertainment, healthcare, industrial manufacturing, cultural heritage, etc.). For that reason, both the reliable generation methods of 3-D models and the need for trained users on such tools are experiencing a growing demand (Ortiz-Sanz et al., 2019).

Photogrammetry is one of the techniques which has dealt since many years with the 3-D reconstruction of real-world objects from images. Among its virtues, it is very portable and it has a much lower cost than other current competitors (e.g. laser scanner). The photogrammetric recording of objects is nearly as old as photography itself, but it has undergone significant changes in parallel to the evolution of technological equipment and methods. Since its origins, photogrammetry has moved from a purely analog, optical-mechanical technique to analytical methods based on computer-aided solutions and mathematical algorithms and finally to digital or modern photogrammetry based on digital imagery and computer vision algorithms.
Traditionally, the education and training in photogrammetry have normally taken place at universities due to the complexity of the analytical processes involved in their teaching and the complex instruments used. However, the modern close-range photogrammetry (CRP) methods make it possible to obtain 3-D models with consumer grade digital cameras or even with mobile phone cameras thanks to the highly automated workflows in software. With this current scenario of ready accessibility, wider and wider public (often amateur users or specialists without a specific training, as archaeologists, architects, advertisers, landscape planners, digital artists, etc.) are using photogrammetric tools and their outcomes in many fields. This fact claims for training actions to be directed to these collectives (Tucci et al., 2018a). The number of initiatives and projects of this type has grown considerably in recent years due to this also growing need for training in the field of photogrammetry (Scaioni et al., 2018; Tucci et al., 2018b; Tucci et al., 2019; Vyas \& Koenig, 2014). Nevertheless, most of these actions are targeted at specialists or university students. With the aim of guaranteeing the existence of future trained sales force it is necessary to put also the focus on high schools, reaching out with these initiatives to prospective students of the 3-D field.

This paper describes the motivation behind the project "D3MOBILE Metrology World League", a STEM (Science, Technology, Engineering and Mathematics) project supported by 
ISPRS as part of the "Educational and Capacity Building Initiative 2020" programme. The project encourages the acquisition of 3-D spatial skills and introduces secondary students around the world to the techniques and principles of photogrammetry or more precisely to the "smartphone-based 3D scanning".

\section{PHOTOGRAMMETRY IN OUR POCKETS}

\subsection{Smartphone-based 3-D scanning}

The use of smartphone-based 3-D scanning is being extensively explored in the professional field taking advantage of the versatility, handling and portability of mobile phones. Samples of application of this technology can be found in very different fields such as architecture and restoration (Russo et al., 2019), accessibility studies (Angelats et al., 2018), forestry (Wu et al., 2019) and even in the medical field (Barbero-García et al., 2019). The present boom in the use of mobile devices as 3-D scanning instruments has also undoubtedly benefited from the evolution of mobile technology itself. Now, smartphones are light, portable and thus with us most of the time, which will inevitably stimulate the spontaneous capture of images with recording purposes (Nocerino et al., 2017). Smartphone camera technology has made significant advances in recent years, by incorporating larger sensors and software with an improved performance, reaching levels of image resolution, sharpness and color accuracy very close to DSLR cameras (Gaiani et al., 2019). The increased quality of images leads to obtain improved 3-D results from them, after being processed with photogrammetric desktop- or cloud-based software. Besides that, the most of current smartphones are now powerful enough to run in almost real time certain 3-D pipelines for themselves through specific apps.

While the acquisition of photographs with the camera of the mobile device is trivial and does not require expertise, the generation of an adequate image set for photogrammetric purposes is not easy at all. In fact, this was one of the limitations of mobile photogrammetry for amateur users using the first generation of camera equipped phones. Both desktop photogrammetric software and apps require a suitable level of overlap between images to ensure the reconstruction and to reach a desired level of accuracy in the 3-D model. With the advent of smartphones and the development of mobile applications, it has been possible to incorporate technologies based on AR (augmented reality) that guide the user to achieve correct camera positions and facilitate the capture of the datasets. Likewise, difficulties in recording objects (i.e. objects with many occlusions and complex shapes, reflective surfaces, etc.) often lead to failure in the matching process, but the influence of these artifacts is difficult to predict in advance while taking the images. Smartphones can partially address these issues by integrating systems which can provide in real-time useful feedback to the user in the course of the reconstruction process and assist him in planning his movements (Kolev et al., 2014).

The mobile photogrammetric solutions can reach similar accuracies than other commonly used methodologies in metrology transforming the mobile phone in a useful and quick measurement tool. However, unlike conventional 2-D distance measurements (e.g. callipers or measurement tapes), the smartphone-based photogrammetry allows for a continuous

More info and downloads: surface to be measured. In terms of accuracy, some comparative studies as (Wrózyński et al., 2017) have also found no significant differences between the 3-D models generated with compact cameras and current mobile phones.

\subsection{Some (almost) free apps}

There are many dedicated apps that can convert a smartphone in a 3-D scanner, but not all of them provide results of the same quality. Moreover, some of the apps require extra hardware (e.g. special lens attachments for the smartphone camera) which turn them into impractical solutions for being used in educational projects in the classroom. Two of the most popular apps for 3-D scanning were selected for being used in the project: (i) Scann3d (SmartMobileVision) and (ii) Qlone (EyeCue Vision Technologies LTD). These apps perform the 3-D reconstruction locally using the internal resources of the mobile device and entirely offline.

i) Scann $3 d^{1}$ is a software piece developed for the Android operating system and based on the OpenMVG (Multiple View Geometry) library (Moulon et al., 2016). The app has a free to use, limited version allowing for the lowest quality (within the options low / medium / high), but usable scans. The premium processing options are available paying a small monthly fee, although for educational purposes these features are not necessary at all. A built-in wizard guides the user while moving around the object and capturing the images by means of anchor points on screen. The app shows green points when the overlap with the previous image is adequate and the user can take the image (Figure 1a). A minimum of 20 images of the scene is required to start processing the $3-\mathrm{D}$ model, which may take a few minutes to complete. Final 3-D models from Scann3d can be exported in the *.obj *.ply or *.stl formats, but only by subscription.
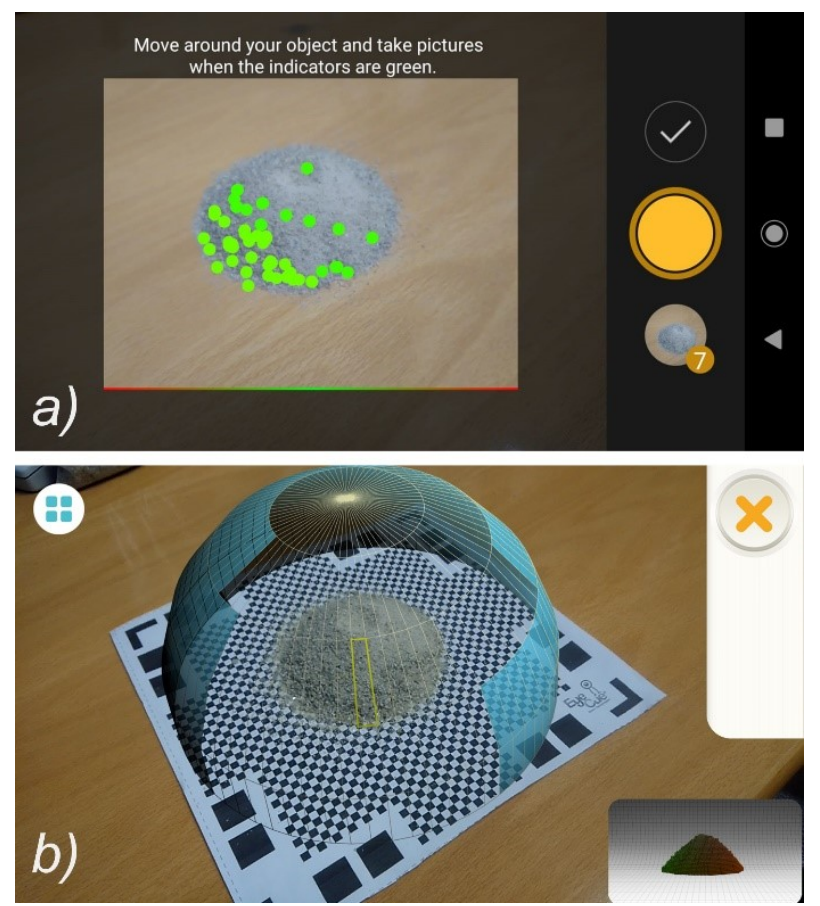

Figure 1. Scann3D (a) and Qlone (b) capturing interfaces.

1

play.google.com/store/apps/details?id=com.smartmobilevisi on.scann $3 \mathrm{~d}$ 
ii) Qlone ${ }^{2}$ is an app initially developed for $\mathrm{iOS}$, though now also runs with Android. Even having free functionalities, this application is also a commercial app as Scann3d and therefore also essentially a "black box". Nevertheless, the technology behind Qlone is slightly different to that of Scann3d. Qlone uses a voxel coloring-based approach (space carving) in combination with AR technology that can convert 2-D images to 3-D models in near real-time. This app requires a printed template with black and white checkerboard and fiducial markers to be included in the scene. In short, the AR tracking algorithms can read the fiducials of this pattern and compute the exterior orientation (pose) between the tracked pattern and the camera. The app generates a virtual dome as a guide for the user, indicating the completed poses around the object (Figure 1b). The template can be scaled to be printed in a larger size format, but in any case, it is a clear limitation for scanning large objects. Contrary to Scann3d, Qlone automatically captures video frames instead of images, so the user just has to move the phone around the object sweeping the whole scene. Like Scann3d, this app allows to purchase extra features which are not available in the free version, such as an exporting tool to save the 3-D model in *.stl/*.obj formats. However, these functionalities are also not essential for educational uses.

Apart from the improved cameras, smartphones are now endowed with a substantial computational power like multi-core processors and dedicated graphic processors that can run these kinds of apps without problems. During the present year 2020 it is expected that some 16 GB RAM can already reach the market. Despite this, the overall 3-D processing capabilities of most of the mobile phones are still far from those of desktop computers. For that reason, we also provide the participants with desktop alternatives for processing the images captured with the mobile phone.

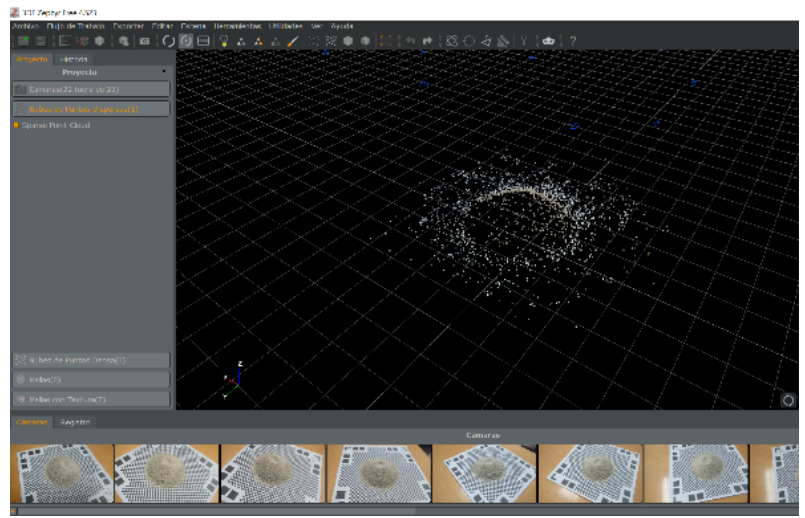

Figure 2. Interface of 3DF Zephyr Free showing one of the steps of the process (sparse point cloud generation).

Among these alternatives is 3DF Zephyr Free ${ }^{3}$ (3DFlow), the free version of a professional software package. This software follows the complete and conventional SfM-MVS (Structure-fromMotion and MultiView Stereo) pipeline for 3-D reconstruction (images $>$ sparse point cloud $>$ dense point cloud $>$ mesh $>$ texture) with a very clear user interface (Figure 2). As most of the professional packages, the software runs with a combination of in-house built technologies (FlowEngine) with the core image processing libraries, including OpenMVG (Multi View Geometry), VisualSFM (Structure From Motion), PMVS/CMVS (Patch-based Multi-View Stereo Software and Clustering views for Multi-View Stereo), MVE (Multi View Environment) and

\footnotetext{
${ }^{2}$ www.qlone.pro/
}

SMVS (Shading aware Multi view Stereo). The free version of this software is limited to the processing of 50 images, but it is ideal for educational aims. These libraries include tools for feature detection, feature matching, bundle adjustment, point cloud extraction and densification, allowing to recover camera poses and deriving 3-D point clouds from an input set of images.

\section{3-D SCANNING IN THE CLASSROOM}

Smartphones represent the most of the times a feared object in the educational environment. Frequently, mobile phones have managed to acquire a bad reputation in the classroom, due to potential distraction and loss of time and even to increase the risk of some misbehaviours like bullying. However, mobile devices can also introduce exciting possibilities when their use is correctly addressed by the teachers to the pupils' learning.

As digital natives, students are now particularly familiar with the use of smartphones, so the integration in the classroom can encourage engagement with the content (Figure 3). Mobile 3-D scanning has already proven to be an appropriate cross discipline suitable for object-based teaching and learning (OBL). This approach challenges the students to develop new knowledge and understanding through interaction with objects, based on a prior understanding (Smith, 2016). Clear successful examples of this kind of educational initiatives comprising 3-D scanning can be encountered in subjects like arts and cultural heritage (Hess et al., 2017) or geology (Dabove et al., 2019; Fernández-Lozano \& Gutiérrez Alonso, 2016).

Despite this, a STEM initiative centred on making understandable the principles of photogrammetry itself can be critical to ensure the reliable and accurate acquisition of 3-D models. At the same time, this project can be useful to introduce concepts associated with metrology and measuring instruments (e.g., accuracy, precision, error, uncertainty, repeatability and reproducibility) which are sometimes difficult to introduce in theoretical lessons without practical examples.

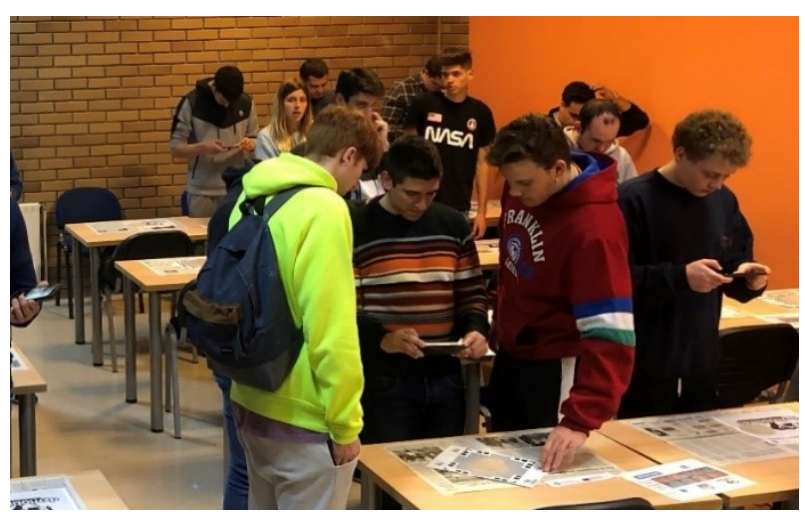

Figure 3. Students practising 3-D scanning with mobile apps in a workshop session

\subsection{D3MOBILE: An e-learning methodology}

The project D3MOBILE Metrology World League is an educational initiative targeted at secondary students (13-18 years old), with a solid background as it has been held annually since 2013 (Gil-Docampo et al., 2019). We have chosen a championship format for this STEM project because competitions give opportunities for the students to think

\footnotetext{
${ }^{3}$ www.3dflow.net/3df-zephyr-pro-3d-models-from-photos/
} 
critically, but they also strengthen the collaborative skills. It is also obvious that keeping students focused on achieving a common and challenging goal (i.e. winning an international championship) is one of the best ways to keep them engaged.

The activities involved in D3MOBILE are developed in the class, under the coordination of a teacher, who creates teams of 2-3 students. Due to the self-explanatory nature of the materials, the role of the teacher is mostly limited to solving a few specific questions. For that reason, the size of the class is usually not a problem to implement the methodology. However, in large classes a general explanation of the activity by the teacher before starting can make tutorials much more demonstrative for the students.

The championship is mainly articulated through the project website $^{4}$ in order to reach as many students as possible wherever they live. With this aim, not only well elaborated online materials, but also flexible schedules are necessary, making the project compatible with the heterogeneous schedules of educational institutions around the world. This is achieved through an extensive registration and delivery period for the results that covers most of the year (registration is permanently open except in summer). In this way, the teachers can coordinate their lessons with the deadlines of the different tests, which are also completely independent of each other.

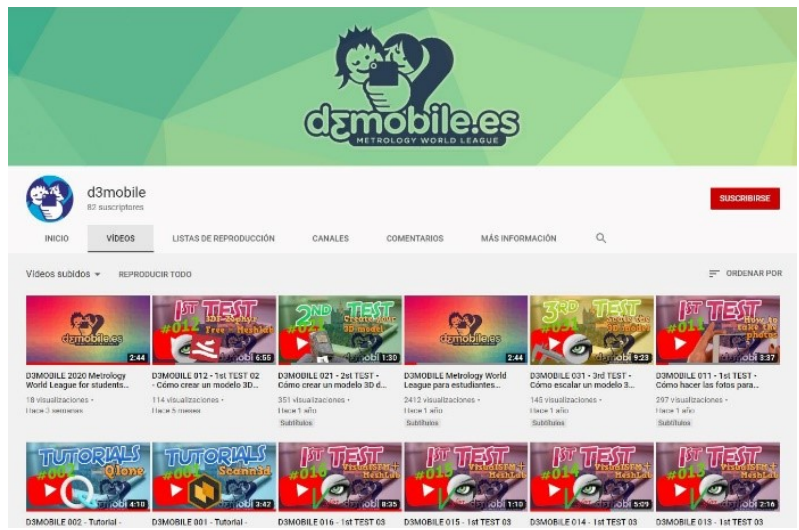

Figure 4. Audio-visual materials created for the championship. Available on YouTube

Being a Project Based e-Learning (PBeL), one of the most important features for the successful implementation of the methodology are the online materials. We present to the students a series of text guidelines following the structure of the project: an introductory tutorial and three additional independent exercises they must complete. Year after year we try to improve these guides at the level of content and making them available in different languages to maximize the international impact of the project. The theoretical content is presented in a scientific, technical, and professional language, but in a more interactive format than that provided by traditional textbooks and classes. On the other hand, the description of the activities is performed step-by-step, including clear diagrams and software screenshots to make them easy to read and understand. Nonetheless, the experience provided by the first years of the D3MOBILE has also led us to recently incorporate audio-visual content in parallel with the text guides as the students find the video more engaging than reading. More than 10 video tutorials have been added to the

\footnotetext{
${ }^{4}$ www.d3mobile.es

${ }^{5}$ www.youtube.com/channel/UCcQUY1pbMi_NJp-Kz-rkB1A
}

collection of project materials (Figure 4), covering the necessary topics to carry out the tests. The list of videos includes "how to take photos correctly", "how to install the necessary software", "how to use the mobile apps Qlone and Scann3D", "how to construct and edit 3-D models using desktop software" and "how to scale a 3-D model from reference distances".

\subsection{The structure of the tests}

The D3MOBILE has a structure comprising three tests. The fact of being independent activities of each other, provides the teachers with higher freedom to decide how to schedule them according to the teaching plan for each subject and each high school.

i. The first test consists in an initial training on 3-D scanning using their own mobile phones and some of the software pieces mentioned above. After being introduced to the principles of photogrammetry and having received some tips to capture the dataset of images, the students are asked to apply these concepts on a real example. A common object (e.g. a sand pile) is proposed to be scanned by all participants. The results of this test are not scored, because it simply has a self-evaluative nature.

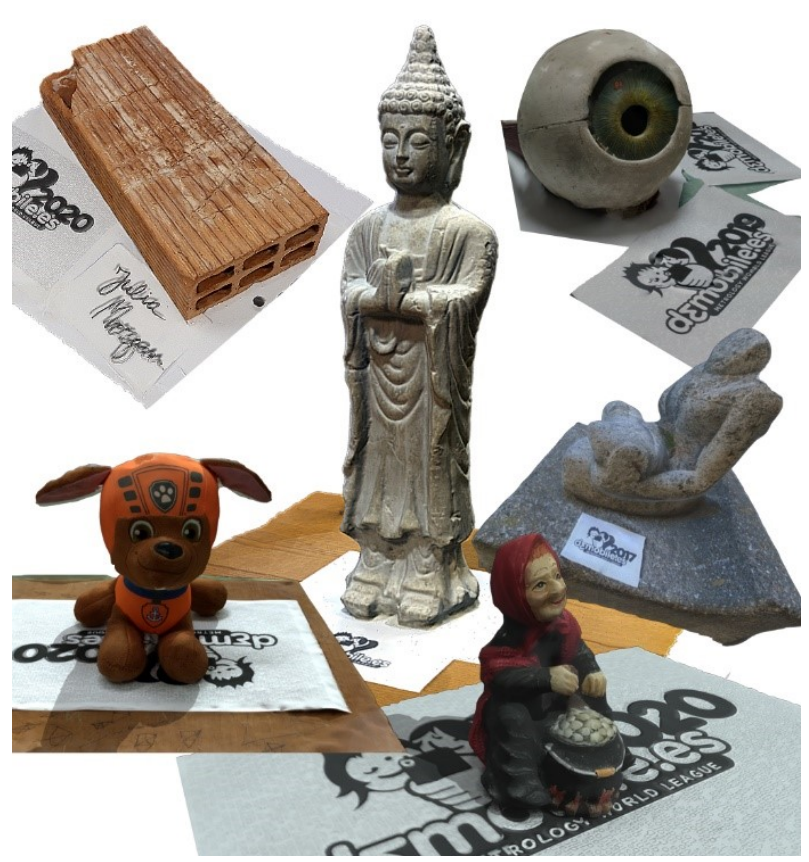

Figure 5. Some samples of scanned objects (available on Sketchfab ${ }^{6}$ ). The complete list of winners by category and year can be found at the D3MOBILE website ${ }^{7}$.

ii. The second test allows the application of 3-D scanning techniques in a freely chosen object (Figure 5). In this case, participants are indicated to take the images with the smartphone and then to use a free desktop software (e.g. 3DF Zephyr Free, VisualSFM, or similar) as the most of mobile apps have limited free possibilities to

\footnotetext{
${ }^{6}$ www.sketchfab.com/d3mobile-m_world_league

${ }^{7} \mathrm{http}: / /$ www.d3mobile.es/ganadores_2019.php
} 
export the 3-D model after being generated. Unlike the first test, this activity also introduces students in a bit more complex post-processing tasks, like cleaning, filtering and editing the generated 3-D triangular meshes. To do so, they are encouraged to use open source software like MeshLab (Cignoni et al., 2008). Finally, once the 3-D model looks how they want it, students are asked to publish it on an online repository like Sketchfab ${ }^{8}$.

iii. The third test is the also called metrology test because its content is focused on the metric assessment of 3-D models. Here the participants have to deal with the concepts associated with the uncertainty in the measurement and the scale. Within this last challenge, a randomly scaled 3-D model is provided by the D3MOBILE staff (Figure 6). Every team must correctly re-scale the model based on reference distances (a calliper has been included within the scene for this purpose). Then they are asked to measure other distances on the correctly scaled model. The results obtained depend on the correct understanding of the previously explained concepts and on the thoroughness in carrying out the scaling procedure. The evaluation of the results of this test is done in a quantitative way.

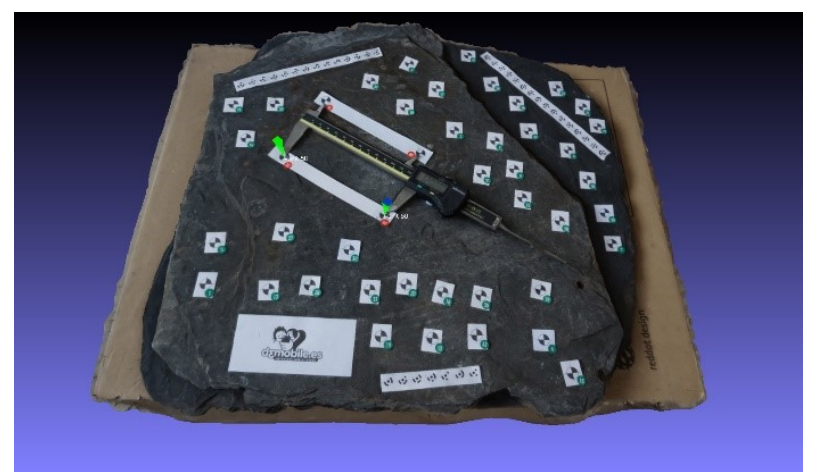

Figure 6. A randomly scaled 3-D model provided to the students for the metrology test. The model includes 40 numbered targets and a calliper as a reference for students, as well as a set of 12bit coded targets for precise and automatic image orientation.

\section{OUTCOMES OF THE PROJECT}

\subsection{Photogrammetry and metrology in the student's curricula}

The participation in D3MOBILE allow students to approach photogrammetry and metrology science with a more practical and less theoretical perspective by means of the integration of different challenges. Particularly, the contents of the three tests are designed to cover respectively the following topics:

i. The basics of photogrammetry. Smartphone-based 3-D scanning. How to take images. Camera requirements and settings. Common problems with this technique (e.g., reflective objects, blurring).

ii. The photogrammetric workflow (images $>$ point cloud $>$ mesh $>$ textured mesh). 3-D Postprocessing. Sharing the results.

iii. Metrology concepts as accuracy vs precision, uncertainty vs error, repeatability vs reproducibility. 3-D coordinate systems and object transformations (translation, scaling and rotation).

At the end of the championship, both the students and the teachers are asked to complete a short survey based on openended questions to evaluate their experience. These questions are great for gathering new ideas and identifying problems that may have arisen. Based on the feedback provided by participants of past editions, the project is believed to meet its initial expectations as a training action. Among the total number of participating teams (i.e. more than 1,500), fewer student's responses were of a meta-analytical nature, and most of them tend to express specific complaints such as the difficulty of some exercises or some software compatibility issues. However, it is also gratifying to see that participants recognize in general that they have learnt about "metrology", "photogrammetry" and "3D techniques". These are some typical quotes:

\begin{abstract}
"We believe that the championship is well planned since it is accessible to everyone who wants to participate and opens up new possibilities for many young people who want to know more about 3-D scanning with mobile phones".
\end{abstract}
"We enjoyed doing this activity because we think it encourages teamwork and it allows to learn about metrology in a more pleasant way."

"I think it's an excellent initiative to promote photogrammetry. I loved knowing the process of 3-D modeling and its applications."

Overall, the response of teachers to the project is also very positive. A better understanding of traditional "hard to teach concepts" compared to those of non-participating students has been highlighted. They also agree pointing out that the students showed a particular "striving for accuracy" with thoroughness and care of the detail in every measurement procedure. A clear example of their involvement can be seen in Figure 7, where the students managed to improve the image-taking process using their available resources and develop their critical thinking.

Infusing engineering concepts into students' curricula through innovative approaches have also highlighted the professional possibilities offered by photogrammetry and 3-D techniques in many fields. Thus, the training programme serves to encourage future students to pursue vocations in those related fields like geomatics or industrial design, with good prospects for job growth.

\footnotetext{
${ }^{8}$ https://sketchfab.com/
} 

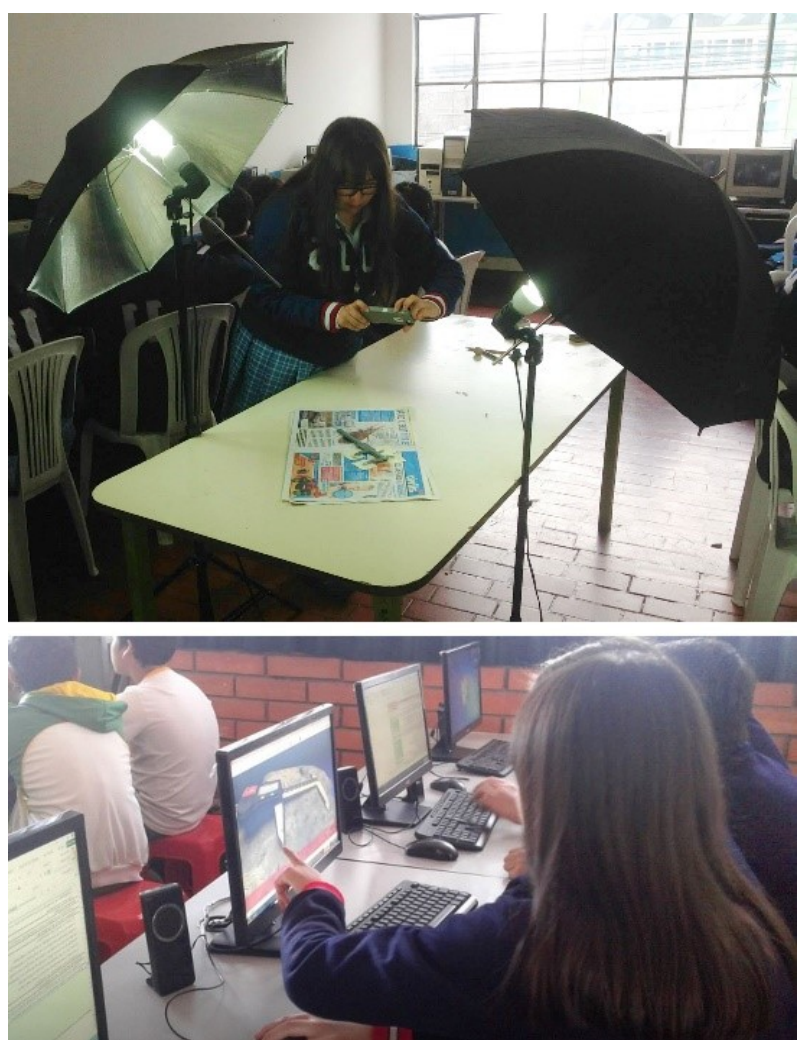

Figure 7. Students learning strategies to measure with their smartphone

\section{Developing skills}

From another viewpoint, the project also tried to be an innovative way of teaching 3-D spatial skills, which are critical to success in a variety of careers, and particularly in those related with engineering. These abilities include the capacity to understand, reason and remember the spatial relations among objects. The STEM projects involving 3-D model creation and edition assist in the development of spatial thinking and favors the creativity of the students.

This initiative also demonstrates to be potentially useful in order to put in practice the "soft skills", those abilities related to people interaction. In general, within high school educational programmes there are rarely classes designed specifically to get them. These skills are difficult to put in practice in a conventional lecture session and they are strongly associated with personal attributes. However, these skills are increasingly valued at any workplace. In this sense, the D3MOBILE is designed as a team competition to reinforce teamwork and the collective thinking capacity of the students. In addition, encouraging lateral thinking and self-direction helps students become adept problem-solvers.

The awards of championship include several categories ranging from the overall prize of $1,200 €$ for the world champion team and other smaller prizes (e.g. tablets, mobile phones, etc.) for specific categories. By incorporating a specific award for "the most voted 3-D model" (800€) we encourage participants to disseminate and promote their own 3-D results among their social environment to get votes. With this, also their communication skills are enhanced and rewarded. We have compiled in the website (http://www.d3mobile.es/vota_promo.php) some samples of these well thought-out social media strategies and elaborated videos which surprise by their originality.

\section{CONCLUSION}

The "D3MOBILE Metrology World League" allows to introduce students with the basics of 3-D scanning and metrology by using their smartphone cameras and dedicated software. Several (almost) free apps, but no means a complete list, with great potential to be integrated into STEM activities at high schools were presented. The project demonstrates how the synergy between science and ICT can catch the attention of the students benefiting their perception of science and improving their skills. Infusing engineering concepts into students' curricula can also promote interest and attract a wide range of prospective students to engineering careers.

\section{REFERENCES}

Angelats, E., Parés, M., \& Kumar, P., 2018. Feasibility of smartphone based photogrammetric point clouds for the generation of accessibility maps. International Archives of the Photogrammetry, Remote Sensing and Spatial Information Sciences - ISPRS Archives, 42(2), 35-41. https://doi.org/10.5194/isprs-archives-XLII-2-35-2018

Barbero-García, I., Lerma, J. L., Miranda, P., \& Marqués-Mateu, A., 2019. Smartphone-based photogrammetric 3D modelling assessment by comparison with radiological medical imaging for cranial deformation analysis. Measurement: Journal of the International Measurement Confederation, 131, 372-379. https://doi.org/10.1016/j.measurement.2018.08.059

Cignoni, P., Callieri, M., Corsini, M., Dellepiane, M., Ganovelli, F., \& Ranzuglia, G., 2008. MeshLab: An open-source mesh processing tool. 6th Eurographics Italian Chapter ConferenceProceedings, 129-136. https://doi.org /10.2312/LocalChapterEvents/ItalChap/ItalianChapConf2008/1 29-136

Dabove, P., Grasso, N., \& Piras, M., 2019. Smartphone-based photogrammetry for the 3D modeling of a geomorphological structure. Applied Sciences, 9(18). https://doi.org/10.3390/app9183884

Fernández-Lozano, J., \& Gutiérrez Alonso, G., 2016. Aula 3.0: Una nueva forma de aprender geología. El uso de las apps Trnio y Skechfab para construir modelos. Enseñanza de Las Ciencias de La Tierra, 24(2), 163-168.

Gaiani, M., Apollonio, F. I., \& Fantini, F., 2019. Evaluating smartphones color fidelity and metric accuracy for the $3 \mathrm{~d}$ documentation of small artifacts. ISPRS Annals of the Photogrammetry, Remote Sensing and Spatial Information Sciences, 42(2/W11), 539-547. https://doi.org/10.5194/isprsArchives-XLII-2-W11-539-2019

Gil-Docampo, M., Ortiz-Sanz, J., Rego-Sanmartin, T., \& ArzaGarcia, M., 2019. A world wide web-based practice that disseminates photogrammetry: Inspiring secondary students to pursue geomatics careers. IEEE Geoscience and Remote Sensing Magazine, 7(1), 86-97. https://doi.org/10.1109/MGRS.2018.2876565

Hess, M., Garside, D., Nelson, T., Robson, S., \& Weyrich, T., 2017. Object-based teaching and learning for a critical 
assessment of digital technologies in arts and cultural heritage. International Archives of the Photogrammetry, Remote Sensing and Spatial Information Sciences - ISPRS Archives, 42(2W5), 349-354. https://doi.org/10.5194/isprs-archives-XLII-2-W5$349-2017$

Kolev, K., Tanskanen, P., Speciale, P., \& Pollefeys, M., 2014. Turning mobile phones into 3D scanners. Proceedings of the IEEE Computer Society Conference on Computer Vision and Pattern Recognition, 3946-3953. https://doi.org/10.1109/CVPR.2014.504

Moulon, P., Monasse, P., Perrot, R., \& Marlet, R., 2016. OpenMVG: Open Multiple View Geometry. 1st Workshop on Reproducible Research in Pattern Recognition, 60-74. https://doi.org/ 10.1007/978-3-319-56414-2_5

Nocerino, E., Lago, F., Morabito, D., Remondino, F., Porzi, L., Poiesi, F., Rota Bulo, S., Chippendale, P., Locher, A., Havlena, M., Van Gool, L., Eder, M., Fötschl, A., Hilsmann, A., Kausch, L., \& Eisert, P., 2017. A smartphone-based 3D pipeline for the creative industry - The replicate EU project. International Archives of the Photogrammetry, Remote Sensing and Spatial Information Sciences - ISPRS Archives, 42(2W3), 535-541. https://doi.org/10.5194/isprs-archives-XLII-2-W3-535-2017

Ortiz-Sanz, J., Gil-Docampo, M., Rego-Sanmartín, T., \& ArzaGarcía, M., 2019. SectorInsights: The Future Professionals in Geomatics. Photogrammetric Engineering \& Remote Sensing, 85(5), 338-339. https://doi.org/10.14358/PERS.85.5.338

Russo, M., Giugliano, A. M., \& Asciutti, M., 2019. Mobile Phone Imaging for CH Façade Modelling. 6th International Workshop LowCost 3D - Sensors, Algorithms, Applications, XLII(December), 2-3. https://doi.org/10.5194/isprs-archivesXLII-2-W17-287-2019

Scaioni, M., Crippa, J., Yordanov, V., Longoni, L., Ivanov, V. I., \& Papini, M., 2018. Some Tools to Support Teaching Photogrammetry for Slope Stability Assessment and Monitoring. International Archives of the Photogrammetry, Remote Sensing and Spatial Information Sciences - ISPRS Archives, 42(3W4), 453-460. https://doi.org/10.5194/isprs-archives-XLII-3-W4-
Smith, D. P., 2016. Active learning in the lecture theatre using 3D printed objects. F1000Research, 5(May). https://doi.org/10.12688/f1000research.7632.2

Tucci, G., Conti, A., Fiorini, L., Panighini, F., \& Parisi, E., 2018a. Education and training resources on digital photogrammetry. International Archives of the Photogrammetry, Remote Sensing and Spatial Information Sciences - ISPRS Archives, 42(5), 45-50. https://doi.org/10.5194/isprs-archivesXLII-5-45-2018

Tucci, G., Conti, A., Fiorini, L., Mei, F., \& Parisi, E. I., 2018b. Digital photogrammetry as a resource for Cuban cultural heritage: Educational experiences and community engagement within the innova Cuba project. International Archives of the Photogrammetry, Remote Sensing and Spatial Information Sciences - ISPRS Archives, 42(5), 37-44. https://doi.org/10.5194/isprs-archives-XLII-5-37-2018

Tucci, G., Parisi, E. I., Conti, A., Corongiu, M., Fiorini, L., \& Panighini, F., 2019. Educational and training experiences in geomatics: tailored approaches for different audience. International Archives of the Photogrammetry, Remote Sensing and Spatial Information Sciences - ISPRS Archives, 42(2)/W11, 1097-1104. https://doi.org/10.5194/isprs-archives-XLII-2-W11$1097-2019$

Vyas, A., \& Koenig, G., 2014. Computer aided teaching in photogrammetry remote sensing and geomatics - A status review. International Archives of the Photogrammetry, Remote Sensing and Spatial Information Sciences - ISPRS Archives, 40(6), 113118. https://doi.org/10.5194/isprsarchives-XL-6-113-2014

Wrózyński, R., Pyszny, K., Sojka, M., Przybyła, C., \& MuratBłazejewska, S., 2017. Ground volume assessment using "Structure from Motion" photogrammetry with a smartphone and a compact camera. Open Geosciences, 9(1), 281-294. https://doi.org/10.1515/geo-2017-0023

Wu, X., Zhou, S., Xu, A., \& Chen, B., 2019. Passive measurement method of tree diameter at breast height using a smartphone. Computers and Electronics in Agriculture, 163(May), 104875. 